\title{
Northwest Native Plants: A Digital Space for Paleoethnobotanical Knowledges and Biocultural Heritage
}

\author{
Molly Carney ${ }^{1 *}$, Melanie Diedrich ${ }^{2}$, John C. Blong ${ }^{1}$, Jade d'Alpoim Guedes ${ }^{3}$, Tiffany J. Fulkerson ${ }^{1}$, Tiffany Kite ${ }^{1}$, \\ Katy Leonard-Doll1', Joyce LeCompte-Mastenbrook ${ }^{4}$, Shannon Tushingham ${ }^{1}$, Mario Zimmerman ${ }^{1}$

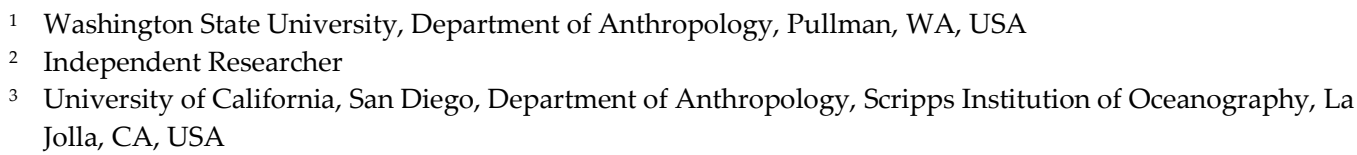

\begin{abstract}
Biocultural heritage preservation relies on ethnobotanical knowledge and the paleoethnobotanical data used in (re)constructing histories of human-biota interactions. Biocultural heritage, defined as the knowledge and practices of Indigenous and Local peoples and their biological relatives, is often guarded information, meant for specific audiences and withheld from other social circles. As such, these forms of heritage and knowledge must also be included in the ongoing data sovereignty discussions and movement. In this paper we share the process and design decisions behind creating an online database for ethnobotanical knowledge and associated paleoethnobotanical data, using a content management system designed to foreground Indigenous and local perspectives. Our main purpose is to suggest the Mukurtu content management system, originally designed for physical items of cultural importance, be considered as a potential tool for digitizing and ethically circulating biocultural heritage, including paleoethnobotanical resources. With this database, we aim to create access to biocultural heritage and paleoethnobotanical considerations for a variety of audiences while also respecting the protected and sensitive natures of Indigenous and local knowledges.
\end{abstract}

Keywords: ethnobotany, paleoethnobotany, biocultural heritage, digital heritage, online database, Indigenous data sovereignty, Open Access, research accessibility, digital reference collection

\section{Introduction}

Paleoethnobotanical data is critical across a wide array of fields but has been particularly helpful in understanding the intersections between environmental change and human adaptive responses [1,2], in dietary reconstructions and gene-culture co-evolutionary processes [2,3], in the agricultural sciences [4,5], in food security [6], in restoration ecology [7-9], and even in strengthening local cultural identities and community connections [10]. Paleoethnobotanical data and knowledge do not just contribute to our collective understanding of human engagements with plants but are part of a group's larger biocultural heritage, inextricably linked to many other realms. The term biocultural heritage is multifaceted as it entails the ancestral rights of Indigenous peoples over the biodiversity they have conserved for generations, and the responsibility to continue to do so for future generations. Paleoethnobotany therefore is a key component within these interdependent and multidisciplinary spheres, cross-cutting past, present, and future approaches to biocultural heritage preservation.

Two major hurdles, however, in the application of paleoethnobotanical data to these larger questions and disciplines are 1) the challenging work of identifying which plants were used in the past and 2) openly sharing biocultural heritage, which is often guarded knowledge within Indigenous and Local Communities. To the first point, archaeologists, 
and even paleoethnobotanists, are not always trained in botany or plant systematics, and the term "plant blindness," the tendency to overlook or ignore plant species, could easily be applied to many of us. Furthermore, when paleoethnobotanical identification criteria do exist for archaeological audiences, it is often couched in expensive or otherwise hard to access articles, books, herbaria, or personal reference collections. Secondly, although well-written and highly accurate ethnobotanical resources and plant identification guides exist, there are some drawbacks to these references. Printed books and monographs are quiescent; reprints and editions offer updates, but the publishing process can take significant time. Ethnographic works may only capture a portion of past people-plant relationships and are not definitive sources on how people engaged with biota throughout time [11]. The cost of printed books also often entails economic barriers to those who are unable to afford these works or other ethnobotanical resources. Finally, these static resources are usually written for specialist audiences and do not often have space or capacity to encompass multiple perspectives, changing viewpoints, or restricted forms of knowledge.

In response to these barriers, we created and now share an online ethnobotanical database website, "Cultural and Historic Guide to Northwest Native Plants" (http://cdscwsu.org/nwnativeplants/), specifically designed to engage and facilitate these intersecting heritage realms. In this piece, we describe our design decisions, content management system choice, and vision for this digital space. Our main purpose is to suggest the Mukurtu content management system (CMS) be considered as one potential tool for digitizing and responsibly circulating biocultural heritage, including paleoethnobotanical resources. Mukurtu is an online platform specifically built around sharing and protecting Indigenous and local knowledge and digitized cultural materials. Although biocultural heritage is most often recorded and archived in published and written formats, we suggest that the Mukurtu CMS offers the potential for varying bodies of biocultural and paleoethnobotanical knowledge and practices to be documented, curated, organized, and ethically shared across social circles while respecting traditional values. In the following sections, we review the open access movement before delving into the data sovereignty dialogue. We then illustrate the potential of digitized biocultural heritage through an example of an online ethnobotanical reference collection and the intersecting communities which engage with these plants.

As with all academic writing, we find it important to state our positions as authors and offer a few caveats on terminology. The ethnobotanical digital project we share below is set within the North American Northwest as several of us (M.C., M.D., T.F., T.K. K.L.D., J.L.M., S.T.) work primarily within this cultural and geographic area. And as we work closely with the Indigenous Peoples and local communities of this region, we are much more familiar with their priorities, projects, commitments, and concerns. We do not claim any authority over Northwest people's ethnobiological heritage, but rather seek to work with these communities to find solutions to joint problems. Many of us (J.C.B, M.C., J.D.G., T.F., J.L.M, K.L.D., M.Z.) are also trained paleoethnobotanists, and we acknowledge that many of our examples will highlight ethnobotany and archaeology. Finally, we follow Fernández-Llamazares, et al. [12] when we refer to biocultural heritage and ethnobotanical knowledge; we are specifically referring to the heritage and knowledge of Indigenous Peoples and local communities in order to recognize their intergenerational connections to place through livelihoods, cultural identities, worldviews, institutions, and ecological knowledge.

\section{Open Access and digital ethnobiology}

Within the western scientific community, the Open Access (OA) movement has sought to change the way knowledge and research are shared and accessed, making the process more equitable for people across varied backgrounds. This movement, which began approximately 20 years ago, advocates for principles and practices that promote freely and easily available research, often shared through online venues [13]. In the traditional academic publishing model, new, peer-reviewed research is typically published in fee- 
based academic journals. When publishing venues do give authors the option of Open Access publishing, it often requires a substantial fee ${ }^{1}$. These fees prohibit many individuals from sharing knowledge in Open Access venues, including practicing professionals, unaffiliated researchers, graduate students, adjunct and clinical faculty, instructors, and lecturers who are often not provided with adequate institutional support and those from institutions, agencies, and programs that do not prioritize or provide the time or resources to pursue publishing. Marginalized/minoritized peoples are disproportionately impacted by these systems - they are more likely to face these and additional barriers to scientific publishing, which impacts the representation of voice in scientific discourses [14-16].

The Open Access (OA) movement, however, seeks to make all research accessible to anyone, thereby keeping the scientific process transparent and reproducible, as well as increasing participation in the scientific process by people who have been historically and systemically excluded [17]. Improved accessibility to scientific research and data is critical to strengthening multivocality and epistemic diversity and should be considered a professional and public responsibility of researchers whose work is supported by public funding [18-20]. Although the Open Access movement most often focuses on keeping scientific journal articles free and widely accessible, it also includes the digitization and organization of scientific datasets in online repositories, libraries, or databases. These digital archives collect, manage, store, and allocate access to data across disciplines, ensuring scientific output is easily accessible to a significant number of people.

Ethnobiology and paleoethnobotany, closely related fields dedicated to the intersection and connections between people and their environments, have also embraced the digital movement and push to open, accessible, and equitable sharing of knowledge $[18,21-23]$. It is well-established that the debilitating consequences of colonialism and marginalization upon Indigenous and local peoples globally have resulted in the significant loss of traditional lifeways, including ethnobiological knowledge [24-27]. Documenting and archiving ethnobiological knowledge for future generations is therefore among the many crucial goals of the discipline [10]. Online reference systems and digital herbaria are increasingly gaining traction as a means of increasing access to wider audiences [23,2833]. Such herbaria, however, are not free from the extractive measures of ongoing, structural colonialism, as the legacy of Linnaean taxonomy has resulted in the relocation of disproportionate number of plant specimens from across the globe into European and North American institutions and their associated systems of knowledge [34]. Within ethnobiology, fewer institutions have their biocultural collections digitized and available online, though the resources that do exist are visited frequently [33].

The lofty goals and outputs of the Open Access movement, however, do not often meet the needs of Indigenous and local communities. To our chagrin, academic scholars have a long history of extracting Indigenous heritage as scientific data and of controlling narratives of Indigenous histories and identities. By administering the academic research process, we have taken cultural heritage and knowledge back to distant institutions for processing into social capital, including publications, expertise, and reputation, and economic capital such as careers, livelihoods, or jobs [35]. This process, termed "parachute science" [36] is extractive and perpetuates colonial relationships and unequal power dynamics, leaving communities with little control over their data and the research outcomes that their knowledge facilitates. Keeping research and data free and not locked behind paywalls is extremely important in ensuring access to members of Indigenous communities and people from all socioeconomic backgrounds, thus facilitating a more inclusive research process [37]. It is further critical that those who work with descendent communities recognize the contributions made by Indigenous and local colleagues in the form of intellectual property rights and ensure equitable access to both archives and any products resulting from these collaborative relationships [33].

${ }^{1}$ Many academic journals do offer discounts or waivers to scholars from specific regions or countries, relieving the economic burden for some individuals, though not all. 
As the OA movement has become established in academic circles, however, many scholars, practitioners, and activists who work closely with Indigenous and local communities are increasingly vocalizing concerns regarding the dilemma between open data and traditional knowledge [38-40]. In many Indigenous epistemologies, certain forms of knowledge are only meant to be shared between members of specific social groups, which are commonly organized by kin, gender, or age. This is particularly salient within ethnobiological contexts - for example, individuals identifying with specific genders will have significantly different engagements with their local environments, plants, and animals, and those cultures will have rules as to how knowledge about those engagements is transmitted [41]. Indeed, many Western Hemisphere Indigenous peoples' worldviews and cosmologies are organized through kincentric belief systems in which all life forms, people, animals, and plants, are considered relatives [42-44]. In these kincentric worldviews, it is the duty and responsibility of humans to look after all other-than-human relatives as their health and well-being are intricately tied to the survival and thrivance of humans. These other-than-human beings have equal priority to people. Thus, biocultural heritage, the knowledge and practices of Indigenous peoples and their biological relatives, is often meant for specific audiences and withheld from other social circles.

The Indigenous data sovereignty movement continues to grow in response to these concerns $[38,39]$. Data sovereignty refers to managing information in a way that is consistent with a community's laws, practices, and customs [45]. For many communities, it is the notion that an Indigenous group should have the right to control the collection, ownership, application, and dissemination of their data [38,39]. Many groups actively oppose or are concerned by the ethical and cultural implications of sharing their people's data without permission or other cultural safeguards. Thus, data sovereignty discussions and projects aim to give power back to the people to determine how their personal information, including heritage and ancestry, is used by academics, governments, and general publics [46]. All Indigenous groups throughout the globe have direct stakes in these conversations, as these varied groups have the right to self-representative, self-determination, and culturally appropriate access to, control over, and preservation of their own biocultural heritage [9]. It is the responsibility of all working in the cultural heritage sector to respect the diverse needs of Indigenous and local communities by actively listening to our collaborators and outlining projects and deliverables that reflect these diverse needs [4750]. In the following section, we consider an online platform designed to do just that.

\section{Databases designed for Indigenous knowledges}

This Mukurtu is a free and open-source platform designed with Indigenous communities to manage and share cultural heritage in a digital form. More specifically, Mukurtu is a content management system (CMS) that reflects relational ways of knowing common in many Indigenous epistemologies; it provides a digital way of organizing and managing access to cultural heritage via relationships and narrative storytelling [51]. The first iteration was built by Kimberly Christen in collaboration with the Warumungu community in Australia. The term mukurtu translates to "safe keeping place," and the platform was originally designed as a database to accommodate social networks and group-based access to sensitive cultural photographs and recordings. However, what started as a smallscale effort to address specific cultural, social, and technological needs among the Warumungu, Mukurtu has since expanded into an open-source CMS platform that has since been adopted by approximately 600 user groups throughout the globe [52,53].

In searching for a host for an accessible yet ethical ethnobotanical database, we chose to use the Mukurtu CMS specifically because the platform is designed to accommodate flexible cultural institutions and culturally sensitive material and immaterial heritage [54]. The Mukurtu CMS offers highly adaptable settings that allow differential access to content, based on a user profile, thus accommodating the many levels of traditional protocols that Indigenous communities use to transfer knowledge [40]. The platform helps to organize what is termed "digital heritage items." What constitutes digital heritage is also 
flexible; it could be an image, video, document, file, etc., but all include additional digital metadata documenting and describing the "item" online.

Mukurtu allows for greater customization and narration through the " $3 c^{\prime} s:$ " the ability to create digital communities, cultural protocols, and digital categories and keywords (Figure 1). In Mukurtu, communities are groups of users and contributors who are linked by some relationship, i.e., social ties, roles, or other defining notions of group membership. Users create accounts that are tied to communities and cultural protocols, which then grant access to specific records and histories. Cultural protocols are rules, in a sense, that determine which members of specific communities have access to some or all aspects of a digital record. These protocols can be defined by gender, seasons, kinship ties, or any other criterion, and are therefore particularly appropriate for many Indigenous communities. Each record can also include traditional knowledge labels to specify these levels of access, use, circulation, and attribution associated with the records and cultural protocols, as well as legally protect intangible cultural heritage materials $[55,56]$. Finally, categories and keywords can be used to describe digital heritage content and allow for easy discovery by users. Combined, the " $3 \mathrm{c}^{\prime} \mathrm{s}$ " allow for the creation of complex relationships and multiple layers of narration, thus creating an online space in which multiple forms of knowledge are encouraged, safeguarded, and accessible in culturally sensitive ways.

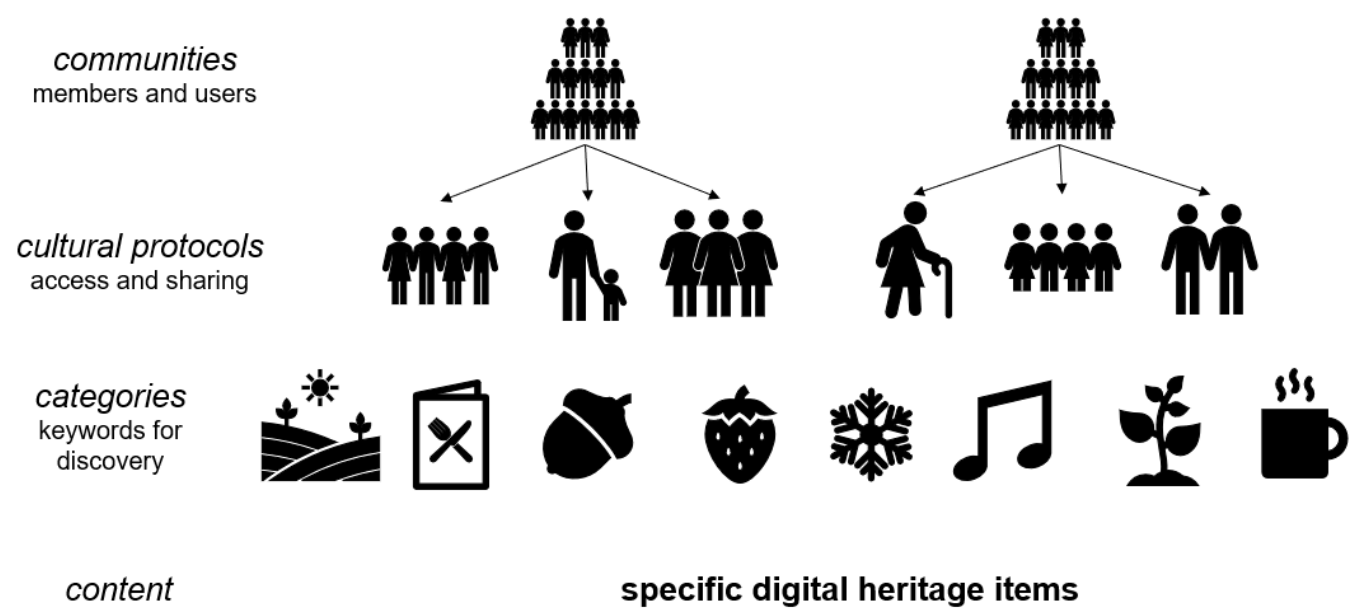

Figure 1. Idealized schematic illustrating the layered organizational structure of Mukurtu. Communities are groups of users who are united by some form of relationship or membership rules. Cultural protocols help to organize those communities by defining who has access to specific digital heritage content. Here, protocols are defined by age and gender. A user can be a member of multiple communities and/or protocols. Finally, categories are useful for organizing and searching for relevant content. Categories can crosscut protocols, communities, and digital heritage items.

\subsection{Adapting Mukurtu to biocultural heritage}

Although Mukurtu was initially conceptualized and designed as a means of digitizing archival collections and repatriating those forms of cultural heritage [51], we see immense value in Mukurtu as a safe-keeping place for biocultural heritage as well. In the following section, we share our experiences in digitizing general ethnobotanical knowledge and paleoethnobotanical data as an example of how such a digital biocultural heritage database might look.

We made several design decisions to accommodate ethnobotanical information and knowledges. Rather than focusing on one item or file, each digital heritage item or record in the Northwest Native Plants database is conceptualized as one plant species. At present, Linnean names are used as the digital heritage record titles and common names are included in the next field to ensure the plant is searchable by people with different taxonomic knowledges. We do, however, recognize that Linnean nomenclature does not 
neatly correspond with folk taxonomies, and one of our future goals is to ensure that other plant species recognized by groups across the greater North American Northwest cultural and geographic region are digitized as well. As of publication, we currently have 41 species uploaded to the website, and are working on more.

For the initial rollout, we also made specific decisions surrounding communities. As of Fall 2021, we consciously chose to keep our communities simple and broad rather than use the names of a specific community; this decision was made to avoid inadvertently highlighting or excluding any tribe or Indigenous group and can be edited in the future to reflect changing user needs. To join a community, a user must create an account with the website and request to join specific communities. Users may also request and nominate administrators for communities to better represent their needs and roles in this digital space. Once a new user has an account and has been added to the appropriate communities, they may create and comment upon digital heritage items, thus producing multiple narratives and allowing for collaborative authorship and individual attribution. By commenting and engaging with digital botanical records, users may engage in storytelling and passing on knowledge and perspectives to their social circles [57].

These communities also have community-specific cultural protocols (Figure 2). For example, our public community includes what we call a General Public protocol. This protocol only allows for generic, common, or already published ethnobotanical knowledge to be visible to all. This includes information to assist identifying the plant outside, photos of the plant in the field and its organs, a summary of the plant's various uses among Northwest groups, and ecology and habitat descriptions. Our paleoethnobotanical practitioner protocol has access to all the above information as well as paleoethnobotanical identification criteria and images. These protocols need not be exclusive; rather we think of them as Venn diagrams in which membership and access overlap across social circles (Figure 2). Again, since the ethnobotanical database is designed to be a flexible and changeable space, there is the potential to add both communities and cultural protocols. If the database sees additional stakeholder buy-in, new protocols can be created to fit user needs and allow various forms of access for members of specific communities (i.e., tribal members, elders, two-spirits, conservationists, non-Indigenous ethnobotanical practitioners, etc.).

Figure 2. Members of the General Public community can belong to one or both of the above cultural protocols, which then dictates access to specific information associated with each biocultural digital heritage item or plant species.

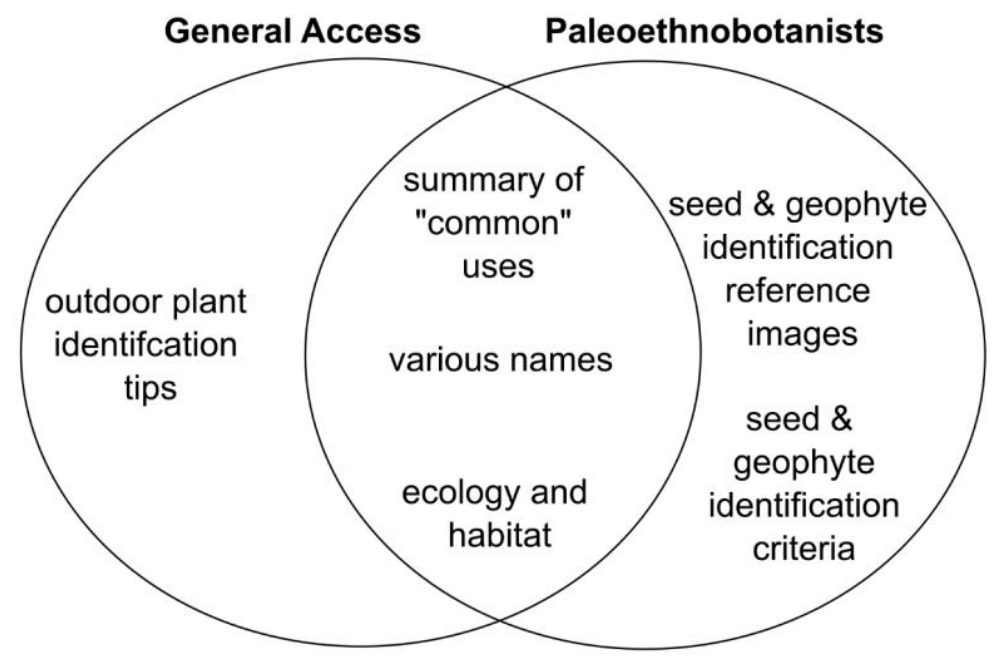

We also use categories to identify whether a plant might be considered food, a seasoning, used as fuel or in technology, or as a medicine. These categories help to narrow down browsing time and searches. Keywords also help to refine those categories further. 
For example, one might be examining the record for biscuitroot (Lomatium cous) and be curious about other edible plants that were prepared in cake form, associated medicinal plants, other members of the Apiaceae family, or just more about edible roots in general. By clicking on keywords, interested parties can track down related topics and plants. And of course, these keywords and categories are flexible, and are easily changed based upon the communities' needs. For example, we envision creating categories and keywords reflective of Salish and Sahaptian linguistic conceptualizations of taxonomic relationships. This flexibility is crucial in working with and accommodating the intricacies of Indigenous knowledge systems worldwide and can be modified to mimic and extend other epistemological and linguistic frameworks.

One might even consider Mukurtu's organizational structure as three-dimensionally rhizomatic. In botany, rhizomes are horizontally growing stems with nodes or buds, and internodes as stem between those nodes. We suggest that biocultural digital heritage items might also be thought of nodes, and the communities, cultural protocols, and categories and keywords as the layered connections or relations, binding, organizing, and directing the entire system (Figure 3). This non-hierarchical model emphasizes relationality over top-down organizational schema. Such a metaphor is fitting as it is the relationships between beings or entities which are key to many forms of Indigenous thinking and knowledge production and dissemination worldwide [58,59], including within North America [60,61]. The Mukurtu CMS, with its flexible organizational structure and emphasis on sharing specific forms of knowledge across defined social circles, is particularly well-suited for digital ethnobotanical databases constructed and maintained with and for community needs. We further see organizing and representing Indigenous biocultural heritage via rhizomatic relationships and connections as another way of returning data

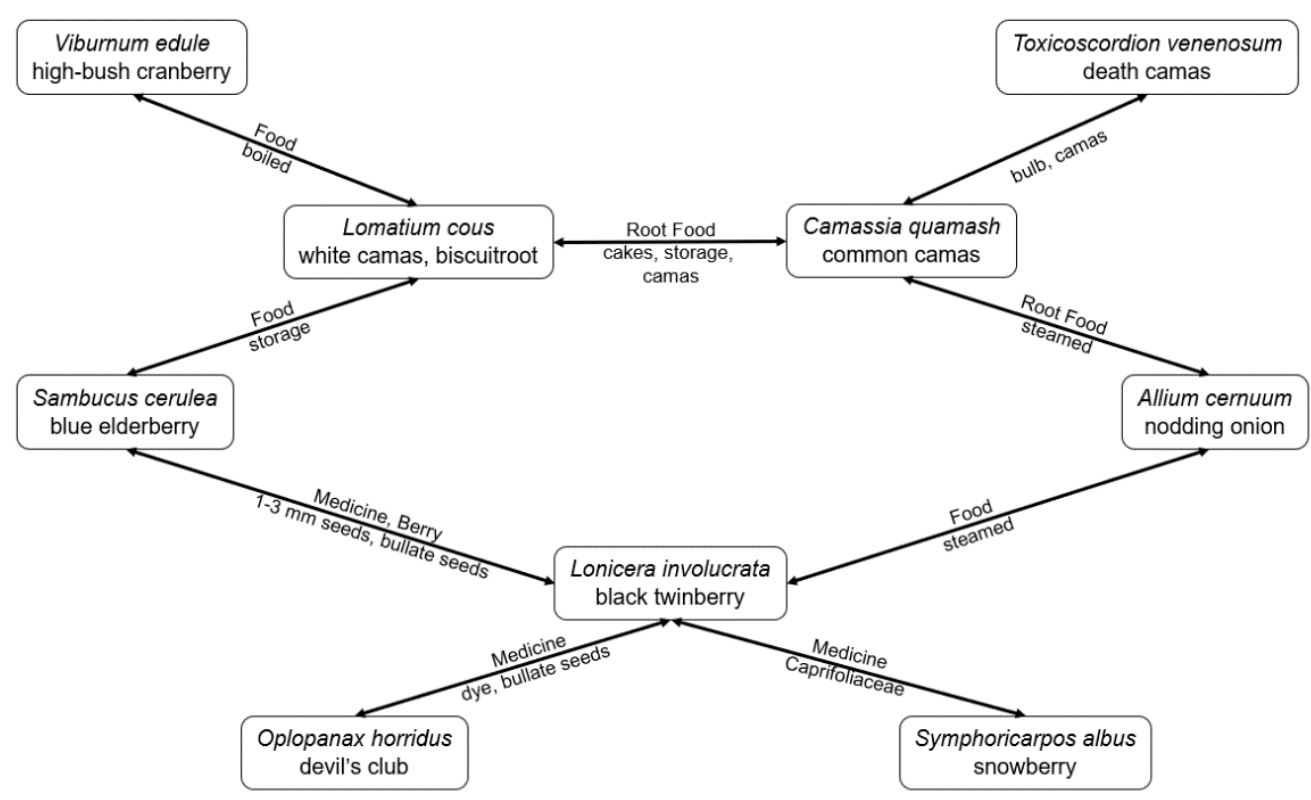

Figure 2. Modified example of relations in the Cultural and Historic Guide to Northwest Native Plants database. Capitalized words on top of arrows indicate categories used to organize plant records while keywords linking each record are beneath the arrows. For example, one method of preparation for nodding onion (Allium cernuum) fruits was through steaming, and black twinberry (Lonicera involucrata) fruits were also cooked with steam. Black twinberry also has bumpy or bullate seeds, similar in texture to the seeds of devil's club (Oplopanax horridus).

sovereignty and autonomy to communities and is therefore another potential tool in the Indigenous digital data sovereignty movement toolkit. We contend that using Mukurtu to host digital biocultural heritage, such as ethnobotanical databases, is an ethical way of working with and for with descendent communities [37,47]. 


\subsection{Paleoethnobotanical considerations}

There is an ongoing demand among paleoethnobotanists and archaeobotanists worldwide for high quality, online, digital reference materials to aid archaeological plant identifications [22,23,62]. Within the North American Northwest, this lack of digital reference materials has demonstrably slowed paleoethnobotanical research and our understandings of regional human-plant relationships [63-65]. One of our initial goals as a group was to find a way to generate digital reference materials and share those materials, so that others could move past the time-consuming act of creating a reference collection and begin the work of identifying plants from the past. Our online database has since evolved to encompass more than just reference images, but we do include that material for a select group of users.

The "Cultural and Historic Guide to Northwest Native Plants" website has a specific cultural protocol just for paleoethnobotanical practitioners, with reference criteria only available to registered users who have been approved to join the protocol by an administrator. While this process does often take several days as it must pass through website administrators, it was a decision made in consultation with tribal collaborators, who also requested that there be some form of safeguard over that material. Members of that protocol will have access to additional reference images and descriptions associated with each ethnobotanical digital heritage item or plant species. These images and descriptions were provided by paleoethnobotanists dedicated to generating such criteria [65-67] and will be constantly updated by the authors of this article as we generate new reference materials.

Members can also follow guidelines on the website to search for specific features they see in archaeological materials. For example, if a researcher finds a $5 \mathrm{~mm}$ long charred seed with a wrinkled or rugose texture, they can use those keywords to review species with similar features. By browsing keywords and examining reference image descriptions, a researcher may identify the mystery seed as Juniperous communis, or common juniper. Pages for each species also include links to other online plant databases, herbaria, and reference databases to assist users in their research. We also included specific search information and guidance within the paleoethnobotanist cultural protocol. Such resources are particularly critical for students learning paleoethnobotany or for smaller practicing researchers, firms, or departments who do not have the resources to curate their own reference collections, thus making the paleoethnobotanical research process much more accessible.

\section{Adapting Northwest Native Plants for the future}

The "Cultural and Historic Guide to Northwest Native Plants" (http://cdscwsu.org/nwnativeplants/) digital ethnobotanical database is still evolving as we continue to add reference material from our own projects and from established comparative libraries [65]. We do not, however, think the website will ever be a "finished product." The online digital space is meant to be an ever-evolving, flexible, and dynamic resource, changing in response to the needs of stakeholders, Indigenous communities, and all others with vested interests in biocultural heritage. As we generate identification criteria and digital images and document ethnobotanical knowledge, new plants will be added to the website. As an organic space that grows with user-submitted content and community engagement, we look forward to seeing how the website evolves in the future. As of 2022, we see at least two potential directions for immediate consideration.

The Mukurtu platform itself is designed with flexibility to accommodate a wide variety of users. We are working with the creators and administrators of Mukurtu to offer a mobile app for the database, allowing users to download the content and use the resources without internet or service. Users can also create content and directly upload to the database, as well as manage and share digital biocultural heritage from their mobile device. We see this development as offering users much more accessible to a wider range of groups and projects. We are also pursuing using the dictionary function of the content management system to provide simple definitions of plant descriptive terms as well as 
Indigenous taxonomic terms for species, subspecies, and varieties that may not fit neatly with western evolutionary relationships and Linnean designations. In this way, we hope to better capture the complexities of Indigenous classification systems and naming conventions $[68,69]$.

Secondly, our team is also working on generating additional reference materials for the paleoethnobotanical comparisons. We plan to continue expanding our macrobotanical work on geophytes while also delving into the underexplored microbotanical world. Microfossils produced by plants also offer an opportunity to explore human-plant relationships in contexts where macrobotanical remains may not preserve or occur, and many new methodological developments work make this line of inquiry increasingly approachable [70]. For example, recent microbotanical work and multiproxy methodological investigations have advanced starch and phytolith identification, our understanding of variabilities in precontact diet, past human management of plants and microenvironments, and shifting paleoenvironments in western North America [71-73]. Yet there is still a great deal to learn about starch grains produced by the region's berries, fruits, seeds, and geophytes, the phytoliths and calcium oxalate crystals associated with regional plant taxa and their organs, the effects of processing plant foods on macro and microbotanical remains, and the related complex biocultural relationships between people and plants throughout deep time. We will also continue to work on uploading the digital seed library by Melanie Diedrich [65], augmenting those comparative materials with some from our own collections, and continue to generate additional macrobotanical reference materials as we delve further into North American Northwest plant systematics.

The website is not intended to replace traditional field guides or reference books, but instead is meant to create access for a variety of audiences in new ways. The website and the Mukurtu content management system democratize the processes of archiving biocultural heritage and generating ethnobotanical knowledge to people across backgrounds. Yet this space also respects the protected and sensitive natures of ethnobotanical and Indigenous knowledges, allowing for culturally nuanced systems of access and sharing. In this way, we hope that communities who choose to engage with these ethnobotanical records will help these plant relations become reanimated and appreciated in new ways.

Author Contributions: Conceptualization, M.C., M.D.; methodology and data curation, J.C.B, M.C., M.D., J.D.G., T.K., T.F., J.L.M, K.L.D., S.T., M.Z.; writing-original draft preparation, M.C.; writingreview and editing, J.C.B, M.C., M.D., J.D.G., T.K., T.F., J.L.M, K.L.D., S.T., M.Z.; All authors have read and agreed to the published version of the manuscript.

Funding: This research was supported by the Washington State University Center for Digital Scholarship and Curation summer fellowship and the Washington Research Foundation.

Data Availability Statement: The website discussed above and biocultural digital heritage items are available at: http://cdsc-wsu.org/nwnativeplants/

Acknowledgments: We wish to thank the staff and partners with both Mukurtu CMS and the Washington State University Center for Digital Scholarship and Curation, including Will Clements, Alex Merrill, Michael Wynne, Kimberly Christen for their insights, ideas, and technical support of this project. Much of the work within this paper was conducted on the homelands of the Nimíipuu (Nez Perce) Tribe and the Palus people and we acknowledge their presence here since time immemorial.

Conflicts of Interest: The authors declare no conflict of interest. 


\section{References}

1. Boivin, N.; Crowther, A. Mobilizing the past to shape a better Anthropocene. Nature Ecology \& Evolution 2021, 5, $273-284$.

2. Purugganan, M.D.; Fuller, D.Q. The nature of selection during plant domestication. Nature 2009, 457, 843-848, doi:10.1038/nature07895.

3. Fuller, D.Q.; Denham, T.; Arroyo-Kalin, M.; Lucas, L.; Stevens, C.J.; Qin, L.i.; Allaby, R.G.; Purugganan, M.D. Convergent evolution and parallelism in plant domestication revealed by an expanding archaeological record. Proceedings of the National Academy of Science, USA 2014, 111, 6147-6152, doi:https://doi.org/10.1073/pnas.1308937110.

4. Fisher, C. Archaeology for Sustainable Agriculture. Journal of Archaeological Research 2019, 28, 393-441, doi:10.1007/s10814-01909138-5.

5. Reed, K.; Ryan, P. Lessons from the past and the future of food. World Archaeology 2019, 51, 1-16, doi:10.1080/00438243.2019.1610492.

6. Logan, A.L.; Stump, D.; Goldstein, S.T.; Orijemie, E.A.; Schoeman, M.H. Usable Pasts Forum: Critically Engaging Food Security. African Archaeological Review 2019, 36, 419-438, doi:10.1007/s10437-019-09347-9.

7. Nicholas, G.P.; Bonneau, N.J.; Westfall, L. Archaeological Approaches to Long-term Secwepemc Plant Use in the Interior Plateau, British Columbia. In Secwepemc People and \{lants: Research Papers in Shuswap Ethnobotany, Ignace, M.B., Turner, N.J., Peacock, S.L., Eds.; Society of Ethnobiology and Shuswap Nation Tribal Council: Tacoma, Washington, 2016; pp. 63-118.

8. Storm, L.; Shebitz, D. Evaluating the Purpose, Extent, and Ecological Restoration Applications of Indigenous Burning Practices in Southwestern Washington. Ecological Restoration 2006, 24, 256-268.

Turner, N.; Spalding, P. "We might go back to this"; drawing on the past to meet the future in northwestern North American Indigenous communities. Ecology and Society 2013, 18, doi:http://dx.doi.org/10.5751/ES-05981-180429.

9. Turner, N.J.; Davidson-Hunt, I.J.; O'Flaherty, M. Living on the Edge: Ecological and Cultural Edges as Sources of Diversity for Social-Ecological Resilience. Human Ecology 2003, 31, 439-461, doi:https://doi.org/10.1023/A:1025023906459.

10. Feinman, G.M.; Neitzel, J.E. Excising culture history from contemporary archaeology. Journal of Anthropological Archaeology 2020, 60, doi:10.1016/j.jaa.2020.101230.

11. Fernández-Llamazares, Á.; Lepofsky, D.; Lertzman, K.; Armstrong, C.G.; Brondizio, E.S.; Gavin, M.C.; Lyver, P.O.B.; Nicholas, G.P.; Pascua, P.a.; Reo, N.J.; et al. Scientists' Warning to Humanity on Threats to Indigenous and Local Knowledge Systems. Journal of Ethnobiology 2021, 41, doi:10.2993/0278-0771-41.2.144.

12. Suber, P. Open access overview. Available online: http://bit.ly/oa-overview (accessed on August 2).

13. Fulkerson, T.J.; Tushingham, S. Who Dominates the Discourses of the Past? Gender, Occupational Affiliation, and Multivocality in North American Archaeology Publishing. American Antiquity 2019, 84, 379-399, doi:10.1017/aaq.2019.35.

14. Heath-Stout, L.E. Who Writes about Archaeology? An Intersectional Study of Authorship in Archaeological Journals. American Antiquity 2020, 85, 407-426, doi:10.1017/aaq.2020.28.

15. Fulkerson, T.J.; Tushingham, S. Making the data count: multivocality and epistemic diversity and injustice in archaeological discourse. In Journal of Field Archaeology, in press, Jalbert, C.L., Heath-Stout, L.E., Eds.; 2022.

16. Nosek, B.A.; Alter, G.; Banks, G.C.; Borsboom, D.; Bowman, S.D.; Breckler, S.J.; Buck, S.; Chambers, C.D.; Chin, G.; Christen sen, G.; et al. Promoting an open research culture. Science 2015, 348, 1422-1425, doi:https://10.1126/science.aab2374.

17. Lepofsky, D.; Heckelsmiller, C.; Fernández-Llamazares, Á.; Wall, J. Seeking a More Ethical Future for Ethnobiology Publishing: A 40-Year Perspective from Journal of ethnobiology. Journal of Ethnobiology 2021, 41, doi:10.2993/0278-0771-41.2.122.

18. Lipe, W.D. Archaeological Values and Resource Management. In Archaeology \& Cultural Resource Management: Visions for the Future, Sebastian, L., Lipe, W.D., Eds.; School for Advanced Research Press: Santa Fe, New Mexico, 2009; pp. 41-63.

19. Else, H. A guide to Plan S: the open-access initiative shaking up science publishing. Nature News Explainer 2021, doi:https://doi.org/10.1038/d41586-021-00883-6.

20. Quave, C.L.; Barfield, K.; Ross, N.; Hall, K.C. The Open Science Network in Ethnobiology: Growing the Influence of Ethnobiology. Ethnobiology Letters 2015, 6, 1-4, doi:10.14237/ebl.6.2015.321.

21. Lodwick, L. Agendas for Archaeobotany in the 21st Century: data, dissemination and new directions. Internet Archaeology 2019, 53, doi:https://doi.org/10.11141/ia.53.7.

22. Warinner, C.; Guedes, J.d.A.; Goode, D. Paleobot.org: establishing open-access online reference collections for archaeobotanical research. Vegetation History and Archaeobotany 2011, 20, 241-244, doi:https://doi.org/10.1007/s00334-011-0282-6.

23. Gorenflo, L.J.; Romaine, S.; Mittermeier, R.A.; Walker-Painemilla, K. Co-occurrence of linguistic and biological diversity in biodiversity hotspots and high biodiversity wilderness areas. Proceedings of the National Academy of Sciences 2012, 109, $8032-8037$.

24. Maffi, L. Linguistic, cultural, and biological diversity. Annu. Rev. Anthropol. 2005, 34, 599-617.

25. Edwards, S.E.; Heinrich, M. Redressing cultural erosion and ecological decline in a far North Queensland aboriginal community (Australia): the Aurukun ethnobiology database project. Environment, Development and Sustainability 2006, 8, 569-583, doi:10.1007/s10668-006-9056-1.

26. Turner, N.J.; Turner, K.L. "Where our women used to get the food": cumulative effects and loss of ethnobotanical knowledge and practice; case study from coastal British ColumbiaThis paper was submitted for the Special Issue on Ethnobotany, inspired by the Ethnobotany Symposium organized by Alain Cuerrier, Montreal Botanical Garden, and held in Montreal at the 2006 annual meeting of the Canadian Botanical Association. Botany 2008, 86, 103-115, doi:10.1139/b07-020.

27. Facility, G.T.G.B.I. What is GBIF? Available online: https://www.gbif.org/what-is-gbif (accessed on 10 September).

28. Cappers, R.T.J.; Bekker, R.M.; Jans, J.E.A. Digital seed atlas of the Netherlands; Barkhuis: Groningen, 2012 ; Volume 4. 
29. Neef, R.; Cappers, R.T.; Bekker, R.M. Digital atlas of economic plants in archaeology; Barkhuis: Gronigen, 2012 ; Volume 17.

30. JSTOR. Global Plants database. Available online: https://plants.jstor.org/ (accessed on

31. BHL. About the Biodiversity Heritage Library. Available online: https://about.biodiversitylibrary.org/ (accessed on

32. Salick, J.; Konchar, K.; Nesbitt, M. Biocultural collections: needs, ethics and goals. In Curating Bio-Cultural Collections: A Handbook, Salick, J., Konchar, K., Nesbitt, M., Eds.; Royal Botanic Gardens Kew Publishing: Kew, London, 2014; pp. 1-14.

33. Park, D.S.; Feng, X.; Akiyama, S.; Ardiyani, M.; Avendaño, N.; Barina, Z.; Bärtschi, B.; Belgrano, M.; Betancur, J.; Bijmoer, R.; et al. The colonial legacy of herbaria. 2021, Preprint available at, doi:https://doi.org/10.1101/2021.10.27.466174.

34. Atalay, S. Indigenous archaeology as decolonizing practice. American Indian Quarterly 2006, 30, $280-310$.

35. Chapman, J.-M.; Algera, D.; Dick, M.; Hawkins, E.E.; Lawrence, M.J.; Lennox, R.-J.; Rous, A.M.; Souliere, C.M.; Stemberger, H.L.J.; Struthers, D.P. Being relevant: Practical guidance for early career researchers interested in solving conservation problems. Global Ecology and Conservation 2015, 4, 334-348.

36. Marwick, B. Open Access to Publications to Expand Participation in Archaeology. Norwegian Archaeological Review 2020, 53, 163169, doi:10.1080/00293652.2020.1837233.

37. Kukutai, T.; Taylor, J., (Eds.) Indigenous Data Sovereignty: Toward an Agenda. Australian National University Press: Centre for Aboriginal Economic Policy Research, The Australian National University, Canberra, 2016.

38. Walter, M.; Kukutai, T.; Carroll, S.R.; Rodriguez-Lonebear, D., (Eds.) Indigenous Data Sovereignty and Policy. Routledge: Taylor \& Francis Group: London and New York, 2021.

39. Christen, K. Does Information Really Want to be Free? Indigenous Knowledge Systems and the Question of Openness. International Journal of Communication 2012, 6, 2870-2893.

40. Pfeiffer, J.M.; Butz, R.J. Assessing Cultural and Ecological Variation in Ethnobiological Research: The Importance of Gender. Journal of Ethnobiology 2005, 25, 240-278.

41. Deloria, B.; Foehner, K.; Scinta, S. Spirit and Reason: The Vine Deloria Jr. Reader; Fulcrum Publishing: Golden Colorado, 1999.

42. Kanngieser, A.; Todd, Z.O.E. 3. From Environmental Case Study to Environmental Kin Study. History and Theory 2020, 59, 385393, doi:10.1111/hith.12166.

43. Salmón, E. Kincentric ecology: indigenous perceptions of the human-nature relationship. Ecological Applications 2000, 5, 13271332.

44. Snipp, C.M. What does data sovereignty imply: what does it look like? In Indigenous Data Sovereignty: Toward an Agenda, Kukutai, T., Taylor, J., Eds.; Centre for Aboriginal Economic Policy Research College of Arts and Social Sciences The Australian National University, Canberra Research Monograph No. 38; Australian National University Press: Canberra, 2016 ; pp. 39-56.

45. Lovett, R.; Lee, V.; Kukutai, T.; Cormack, D.; Rainie, S.C.; Walker, J. Good data practices for indigenous data sovereignty. In Good Data, Daly, A., Devitt, S.K., Mann, M., Eds.; Institute of Network Cultures Inc.: Amsterdam, 2019.

46. Atalay, S. Community-based archaeology: Research with, by, and for indigenous and local communities; Univ of California Press: 2012.

47. Colwell-Chanthaphonh, C.; Ferguson, T.J.; Lippert, D.; McGuire, R.H.; Nicholas, G.P.; Watkins, J.E.; Zimmerman, L.J. The Premise and Promise of Indigenous Archaeology. American Antiquity 2010, 75, 228-238.

48. McAlvay, A.C.; Armstrong, C.G.; Baker, J.; Elk, L.B.; Bosco, S.; Hanazaki, N.; Joseph, L.; Martínez-Cruz, T.E.; Nesbitt, M.; Palmer, M.A.; et al. Ethnobiology Phase VI: Decolonizing Institutions, Projects, and Scholarship. Journal of Ethnobiology 2021, 41, doi:10.2993/0278-0771-41.2.170.

49. Fulkerson, T.J.; Tushingham, S. Cultural Heritage and the Expropriation and Appropriation of Indigenous Knowledge, Materials, and Lands: Collaboration and Communication Considerations for LandGrant Institutions. In How do we Reach More? Sharing Cultural and Archaeological Research with Others, Stapp, D.C., Longnecker, J.G., Eds.; Journal of Northwest Anthropology Special Publication; Journal of Northwest Anthropology: Richland, Washington, 2021; pp. 221-232.

50. Christen, K. “The songline is alive in Mukurtu": Return, reuse, and respect. In Archival returns: Central Australia and beyond, Barwick, L., Green, J., Vaarzon-Morel, P., Eds.; Language Documentation \& Conservation Special Publication; Sydeny University Press: Sydney, 2019; Volume 18, pp. 153-172.

51. Christen, K.; Merrill, A.; Wynne, M. A Community of Relations: Mukurtu Hubs and Spokes. D-Lib Magazine $2017,23$.

52. Karuk, T.; Hillman, L.; Hillman, L.; Harling, A.R.S.; Talley, B.; McLaughlin, A. Building Sípnuuk: A Digital Library, Archives, and Museum for Indigenous Peoples. Collection Management 2017, 42, 294-316, doi:10.1080/01462679.2017.1331870.

53. Christen, K. Relationships Not Records: Digital Heritage and the Ethics of Sharing Indigenous Knowledge Online. In Routledge Companion to Media Studies and Digital Humanities, edited by Jentery Sayers. Routledge: Taylor and Francis, 2018, pp. 403-412., Sayers, J., Ed.; Routledge: Taylor and Francis: Oxfordshire, 2018.

54. Anderson, J.; Christen, K. 'Chuck a copyright on it': Dilemmas of digital return and the possibilities for Traditional Knowledge licenses and labels. Museum Anthropology Review 2013, 7, 105-126.

55. Anderson, J.; McElgunn, H.; Richland, J. Labeling knowledge: The semiotics of immaterial cultural property and the production of new indigenous publics. In Engaging Native American Publics, Kroskrity, P.V., Meek, B.A., Eds.; Routledge: London, 2017; pp. 184-204.

56. Bishop, L.S. Native American perspectives on biocultural collections and cultural restoration. In Curating Bio-Cultural Collections: A Handbook, Salick, J., Konchar, K., Nesbitt, M., Eds.; Royal Botanic Gardens Kew Publishing: Kew, London, 2014; pp. 259262.

57. Kohn, E. How forests think: Toward an anthropology beyond the human; Univ of California Press: 2013.

58. Marshall, Y. Indigenous Theory is Theory: Whakapapa for Archaeologists. Cambridge Archaeological Journal 2021, 31, 515-524, doi:10.1017/s0959774321000214. 
59. Cordova, V.F. How It Is: The Native American Philosophy of VF Cordova; University of Arizona Press: 2007.

60. Cajete, G. Native science: Natural laws of interdependence; Clear Light Books: Santa Fe, New Mexico, 2000.

61. Miller, N.F. Archaeobotanical methodology: results of an archaeobotany questionnaire. The SAA Archaeological Record 2011, 11, 8-10.

62. Lepofsky, D.; Peacock, S.L. A question of intensity: exploring the role of plant foods in northern Plateau prehistory. In Complex hunter-gatherers: evolution and organization of prehistoric communities on the Plateau of northwestern North America, Prentiss, W.C., Kujit, I., Eds.; University of Utah Press: Salt Lake City, Utah, 2004; pp. 115-139.

63. Lepofsky, D.; Lyons, N. THE SECRET PAST LIFE OF PLANTS: Paleoethnobotany in British Columbia. BC Studies 2013, 179, 3955.

64. Diedrich, M. Pacific Northwest Paleobotany: Native Seeds and the Creation of a Comparative Library. Archaeology in Washington 2008, 14, 21-35.

65. Carney, M.; d'Alpoim Guedes, J. Paleoethnobotanical identification criteria for bulbs of the North American Northwest. Vegetation History and Archaeobotany 2021, doi:https://doi.org/10.1007/s00334-020-00808-9.

66. Friedman, J. Wood identification by microscopic examination: A guide for the archaeologist on the Northwest coast of North America; British Columbia Provincial Museum: 1978.

67. Hunn, E.S. The Utilitarian Factor in Folk Biological Classification. American Anthropologist 1982, 84, 830-847.

68. Turner, N.J. Ancient Pathways, Ancestral Knowledge: Ethnobotany and Ecological Wisdom of Indigenous Peoples of Northwestern North America; McGill-Queen's University Press: Montreal, Quebec, 2014; Volume 1.

69. VanDerwarker, A.M.; Bardolph, D.N.; Hoppa, K.M.; Thakar, H.B.; Martin, L.S.; Jaqua, A.L.; Biwer, M.E.; Gill, K.M. New World Paleoethnobotany in the New Millennium (2000-2013). Journal of Archaeological Research 2016, 24, 125-177, doi:10.1007/s10814015-9089-9.

70. Louderback, L.A.; Herzog, N.M.; Pavlik, B.M. A new approach for identifying starch granules of wild food plants from arid western North America. Starch - Stärke 2017, 69, doi:10.1002/star.201600167.

71. Blong, J.C.; Adams, M.E.; Sanchez, G.; Jenkins, D.L.; Bull, I.D.; Shillito, L.-M. Younger Dryas and early Holocene subsistence in the northern Great Basin: multiproxy analysis of coprolites from the Paisley Caves, Oregon, USA. Archaeological and Anthropological Sciences 2020, 12, doi:10.1007/s12520-020-01160-9.

72. Damick, A.; Rosen, A.; Ortman, S. Palm springs on the Rio Grande: Insight into Archaic forager plant use from phytoliths recovered from a Late Holocene alluvial section in northern New Mexico. PLoS One 2021, 16, e0258231, doi:10.1371/journal.pone.0258231. 